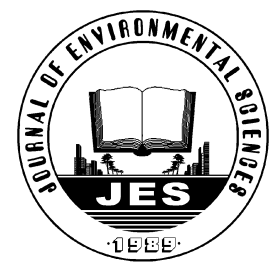

\title{
Combined effects of cadmium and fluoranthene on germination, growth and photosynthesis of soybean seedlings
}

\author{
Qiushuang $\mathrm{Li}^{1,2}$, Yonglong $\mathrm{Lu}^{1, *}$, Yajuan $\mathrm{Shi}^{1}$, Tieyu Wang ${ }^{1}$, Kun $\mathrm{Ni}^{1,2}$, \\ $\mathrm{Li} \mathrm{Xu}^{1,2}$, Shijie Liu ${ }^{1,2}$, Lin Wang ${ }^{1,2}$, Qinli Xiong ${ }^{1}$, John. P Giesy ${ }^{3}$ \\ 1. State Key Laboratory of Urban and Regional Ecology, Research Center for Eco-Environmental Sciences, Chinese Academy of Sciences, Beijing \\ 100085, China. E-mail: qiushuang.li@gmail.com \\ 2. University of Chinese Academy of Sciences, Beijing 100039, China \\ 3 Department of Veterinary Biomedical Sciences and Toxicology Centre, University of Saskatchewan, Canada
}

Received 25 December 2012; revised 06 February 2013; accepted 01 April 2013

\begin{abstract}
The single and combinational effects of cadmium (Cd) and fluoranthene (FLT) on germination, growth and photosynthesis of soybean seedlings were investigated. Exposure to 5,10 , or $15 \mathrm{mg} \mathrm{Cd} / \mathrm{L}$ or 1,5 , or $10 \mathrm{mg}$ FLT/L individually or in combination significantly decreased germination vigor ( 3 days) and final germination rate of soybean seeds, except at 1 and $5 \mathrm{mg}$ FLT/L. The results of two-way ANOVA analysis and the Bliss independence model showed that at lower concentrations of FLT $(1 \mathrm{mg} / \mathrm{L})$, the interaction between Cd and FLT on germination was antagonistic, whereas the interaction was synergistic when the concentration of FLT was 5 or $10 \mathrm{mg} / \mathrm{L}$ and the concentration of $\mathrm{Cd}$ was $15 \mathrm{mg} / \mathrm{L}$. Growth, expressed as dry weight, length of shoot and root, leaf area, and photosynthesis, expressed as net photosynthetic rate, intercellular $\mathrm{CO}_{2}$ concentration, chlorophyll contents and fluorescence of soybean seedlings were also reduced by exposure to 5 or $10 \mathrm{mg} \mathrm{Cd} / \mathrm{L}$ or 1 or $5 \mathrm{mg} \mathrm{FLT/L}$, singly or jointly. Significant antagonistic effects of exposure to 5 or $10 \mathrm{mg} \mathrm{Cd} / \mathrm{L}$ or 1 or $5 \mathrm{mg} \mathrm{FLT/L} \mathrm{on} \mathrm{shoot} \mathrm{growth} \mathrm{and} \mathrm{photosynthesis} \mathrm{were} \mathrm{observed,} \mathrm{whereas} \mathrm{synergy} \mathrm{and} \mathrm{antagonism} \mathrm{of} \mathrm{Cd} \mathrm{and} \mathrm{FLT}$ were both observed for root growth.
\end{abstract}

Key words: synergism; antagonism; metal; PAH; photosynthesis; plant; toxicity

DOI: $10.1016 / \mathrm{S} 1001-0742(12) 60264-2$

\section{Introduction}

Cadmium (Cd) and polycyclic aromatic hydrocarbons (PAHs) are two of the most abundant and potentially harmful pollutants found in polluted soils and due to the rapid urbanization and industrialization, concentrations of both chemicals have increased in China during the past decade (Sun et al., 2011). Increasing concentrations of $\mathrm{Cd}$ in soils represent a threat to plants because of its mobility and phytotoxicity (Wahid et al., 2010). PAHs, a group of priority pollutants suggested by US EPA, are frequently detected at varying concentrations in agricultural and urban soils worldwide (Tao et al., 2004; Nam et al., 2008; Maliszewska-Kordybach et al., 2009). Fluoranthene (FLT) is a typical PAH that is ubiquitous and widespread in the environment (Bryselbout et al., 2000). It can also enter plant tissues by uptake through the roots from contaminated soils and can then be moved into shoots (Oguntimehin et al., 2010). Effects of FLT on higher plants have been

\footnotetext{
* Corresponding author. E-mail: yllu@ @rcees.ac.cn
}

reported previously (Huang et al., 1997; Oguntimehin et al., 2010; Kummerová et al., 2013).

Unlike under laboratory conditions, plants in nature are rarely exposed to a single hazardous chemical. Cadmium and PAHs are often found together in contaminated soils. However, much of the information on adverse effect of environmental contaminants on plants has focused on exposure to $\mathrm{Cd}$ or individual PAHs and there is little information available on their combined effects on terrestrial plants.

Soybean (Glycine max) is an important economic crop that has been reported to be sensitive to the effects of Cd (Finger-Teixeira et al., 2010), and FLT can also affect photosynthesis and growth of legumes (Váňová et al., 2009). Therefore, effects of Cd and FLT, singly and in combination on the germination, growth and photosynthesis of soybean seedlings were investigated in the present study. The measurement indices were germination vigor, germination rate, dry weight, length of shoot and root, leaf area, chlorophyll content, gas exchange and chlorophyll 


\section{fluorescence.}

The literature on combined-effect analysis is dominated by terms like additive, synergistic and antagonistic effect The term additive effect is used to describe the situation of no interaction between components. Toxic potency greater than additive is termed synergistic, while the term antagonistic is commonly used to describe infra-additive toxicity that has potency less than the predicted additive effect (Könemann and Pieters, 1996). Various models have been used to assess combined effects of mixtures on organisms. The major theoretical foundation of these models can be traced back to two distinct origins: Loewe additivity and Bliss independence (Loewe and Muischnek, 1926; Bliss, 1939). Loewe additivity considers that each component in a mixture has an identical molecular mechanism and hence behaves in the same way and reaches the same biological target. Alternatively, Bliss independence is based on the assumption that the mode of action and possibly, but not necessarily, the characteristic and the site of effects can differ among toxicants in mixtures. Cadmium and FLT have different chemical properties and previous studies have indicated that they also have different mechanisms of toxic action on plants (Faller et al., 2005; Kummerová et al., 2006). Thus, in this study, after determining the significance of the interaction between effects of $\mathrm{Cd}$ and FLT on soybean seedlings, the Bliss independence model was applied to evaluate the type of combined effects.

\section{Materials and methods}

\subsection{Germination}

Fluoranthene (Supelco, USA) was previously dissolved in acetone (Fisher, USA) and delivered to filter-purified water $\left(\mathrm{FP}-\mathrm{H}_{2} \mathrm{O}\right)$ to a concentration of $1 \mathrm{~g} / \mathrm{L}$. Cadmium $\left(\mathrm{CdCl}_{2}\right.$, analytical grade; TCI, China) was dissolved in $\mathrm{FP}-\mathrm{H}_{2} \mathrm{O}$ to a concentration of $1 \mathrm{~g} / \mathrm{L} \mathrm{Cd}$. FLT and cadmium stock solution were diluted with $\mathrm{FP}-\mathrm{H}_{2} \mathrm{O}$ to final concentrations. The results of preliminary experiments demonstrated that the concentration of acetone in the solvent did not affect germination, but control seeds were always exposed to the same concentration of acetone.

Uniform and healthy soybean seeds (Glycine max Zhonghuang 30, Chinese Academy of Agricultural Sciences) were soaked in $10 \% \mathrm{H}_{2} \mathrm{O}_{2}$ for $15 \mathrm{~min}$, rinsed five times with $\mathrm{FP}-\mathrm{H}_{2} \mathrm{O}$. After $8 \mathrm{hr}$ of soaking in $\mathrm{FP}-\mathrm{H}_{2} \mathrm{O}, 15$ seeds were placed in Petri dishes on 2 pieces of filter paper with $10 \mathrm{~mL}$ of each solution. All treatments were repeated five times. Seeds were germinated in a growth chamber under controlled conditions (dark, mean air temperature $25^{\circ} \mathrm{C}$, relative air humidity $80 \%$ ). Germination vigor $(\mathrm{GV})$ and final germination rate (GR) of seeds are the percentage of germinating seeds related to number of planted seeds after 3 and 7 days respectively (Willan et al., 1985). Seed germination was defined as formation of roots (at least 5 mm long).

\subsection{Nutrient solution preparation}

Fluoranthene (FLT; Supelco, USA) was dissolved in acetone (Fisher, USA) and FP-water $(1: 99, V / V)$ to $1 \mathrm{~g} \mathrm{FLT/L}$ with $\mathrm{CdCl}_{2}$ dissolved in $\mathrm{FP}$-water to $1 \mathrm{~g} \mathrm{Cd} / \mathrm{L}$. Stock solution was diluted with Hoagland's solution (Hoagland and Arnon, 1950) to final concentrations. The experimental design was a factorial with the following treatments: (1) blank control: soybean seedlings were cultured in the Hoagland's solution without any addition of chemicals; (2) solvent control with $1 \%$ acetone; (3) individual treatments of 5 or $10 \mathrm{mg} \mathrm{Cd} / \mathrm{L}$; (4) individual treatments of 1 or 5 mg FLT/L; (5) complete factorial treatments with binary combinations of Cd and FLT: $(5 \mathrm{mg} \mathrm{Cd} / \mathrm{L}+1 \mathrm{mg} \mathrm{FLT/L}$; $10 \mathrm{mg} \mathrm{Cd} / \mathrm{L}+1 \mathrm{mg} \mathrm{FLT/L} ; 5 \mathrm{mg} \mathrm{Cd} / \mathrm{L}+5 \mathrm{mg} \mathrm{FLT} / \mathrm{L} ; 10$ $\mathrm{mg} \mathrm{Cd} / \mathrm{L}+5 \mathrm{mg} \mathrm{FLT} / \mathrm{L})$. All treatments were replicated four times and there were four soybean seedlings in each replicate.

\subsection{Plant cultivation}

Surface of uniform and healthy soybean seeds was disinfested in $10 \% \mathrm{H}_{2} \mathrm{O}_{2}$ for $15 \mathrm{~min}$ and germinated in sterile trays with 1 piece of moist filter paper and 4 layers of gauze. After 4 days of germination in growth chamber under controlled conditions (mean air temperature $25^{\circ} \mathrm{C}$, relative air humidity $80 \%$ ), seeds were transplanted into containers containing $1 / 4$ strength Hoagland's solution for cultivation. When two true leaves were developed, the 7day-old seedlings were transplanted into glass containers (4 seedlings per container) with $500 \mathrm{~mL}$ prepared solution and cultivated for another 12 days period.

Containers were wrapped with shading paper to eliminate photolysis of FLT and positioned randomly and re-randomized every day. During cultivation, the medium was saturated with oxygen to reduce the metabolism of anaerobic microorganisms. Cultivation was done under natural light with a maximum irradiance of 400 $\mu \mathrm{mol} /\left(\mathrm{m}^{2} \cdot \mathrm{sec}\right)$ of photosynthetic active radiation (PAR) in an air-conditioned glasshouse at an average air temperature of $(28 \pm 2)^{\circ} \mathrm{C}$ and relative air humidity from $60 \%$ to $80 \%$. The nutrient solution was renewed every 2 days and its $\mathrm{pH}$ value was regularly adjusted to 6.5 .

\subsection{Gas exchange and chlorophyll fluorescence param- eters}

After exposure to pollutants for 11 days, at the second fully expanded trifolium (diagnostic leaf), photosynthetic parameters including photosynthetic rate $(\mathrm{Pn})$, stomatal conductance $(\mathrm{Gs})$, intercellular $\mathrm{CO}_{2}$ concentration $\left(C_{\mathrm{i}}\right)$ were recorded by infrared gas analysis (IRGA) of an open-path, portable photosynthesis system (LI-6400, LICOR, Lincoln, USA) and calculated by use of previously published equations (Farquhar et al., 1980). Leaves of two plants per repetition were measured and 15 records were made for each leaf. A chlorophyll fluorometer chamber (LI-6400-40; LI-COR, Lincoln, NE, USA) was integrat- 
ed on pulse-amplitude modulated with the LI6400XT to evaluate the fluorescence parameters. LI6400-40 has a sampling area of $2 \mathrm{~cm}^{2}$ and an internal red-blue LED light source that was used to obtain the desired photosynthetic photo flux density (PPFD) and make measurements of fluorescence of chlorophyl. Leaves were dark-adapted for $80 \mathrm{~min}$ before each measurement. Initial fluorescence $\left(F_{0}\right)$ was measured by using a modulated beam of 0.25 $\mathrm{kHz}$. Modulation frequency of measuring light was then increased to $20 \mathrm{kHz}$ and superimposed with $0.8 \mathrm{sec}$ pulses of saturating pulses, and maximal fluorescence $\left(F_{\mathrm{m}}\right)$ was determined. The quantum yield of photosystem II photochemistry ( $\varphi_{\text {PSII }}$ ) was calculated (Eq. (1)).

$\varphi_{\text {PSII }}=F_{\mathrm{m}}{ }^{\prime}-F_{\mathrm{s}} / F_{\mathrm{m}}{ }^{\prime}$

where $F_{\mathrm{m}}{ }^{\prime}$ is the maximal fluorescence in the light during a saturating light flash and $F_{\mathrm{s}}$ is 'steady-state' fluorescence in the light (Genty et al., 1989).

All of the photosynthetic measurements were made at a constant air flow rate of $500 \mu \mathrm{mol} / \mathrm{sec}$. The concentration of $\mathrm{CO}_{2}$ was $(400 \pm 2) \mu \mathrm{mol} \mathrm{CO} \mathrm{CO}_{2} / \mathrm{mol}$ air using the system's $\mathrm{CO}_{2}$ injector (Li-6400-01, Li-COR), and the temperature was maintained at $(28 \pm 2)^{\circ} \mathrm{C}$. IRGA was calibrated to provide similar leaf and air temperature within the sample chamber at a constant PPFD of $1500 \mu \mathrm{mol} /\left(\mathrm{m}^{2} \cdot \mathrm{sec}\right)$. Leaves of two plants per repetition were measured for all the chlorophyll fluorescence parameters.

\subsection{Chlorophyll content}

Two leaf discs of $0.9 \mathrm{~mm}$ diameter were collected at the second fully expanded true leaves after the seedlings were exposed to pollutants for 12 days. Leaves of two plants were included in each replicate. Leaves of soybean were soaked in $80 \%$ acetone, and the chlorophyll was extracted. The extract was centrifuged at $5300 \times g$ for 10 min. Then absorbance of the supernatant was determined at 645 and $663 \mathrm{~nm}$, respectively. Measurements of each sample were repeated 3 times. The content of chlorophyll was calculated according to Lichtenthaler (1987).

\subsection{Growth indices}

After exposed to pollutants for 12 days, length of shoot and root of each soybean seedling were measured. Leaf area was measured at the second fully expanded true leaves of each seedling by graph paper method. Seedlings were separated into roots, shoots and stems, rinsed 3 times with FP- $\mathrm{H}_{2} \mathrm{O}$ then dried with disinfected absorbent cotton and collected. After lyophilization for $48 \mathrm{hr}$, dry weight was measured.

\subsection{Statistical analysis}

Results were reported as the mean of four repetitions of each concentration. Data were checked for normality and homogeneity of variance using Kolmogorov-Smirnovone- sample test and Levene's test, respectively. When necessary, data were transformed for normalization and to reduce heterogeneity of variance. Differences among treatments were analyzed by the one-way analysis of variance (ANOVA). The significance of interactions between $\mathrm{Cd}$ and FLT were analyzed by use of two-way ANOVA. The least significant difference (LSD) was applied to determine the significance between different treatments. All statistical analyses were carried out using SPSS 13.0 (SPSS, Chicago, USA). The critical value for statistical significance was $p<0.05$. The analysis of type of interaction of $\mathrm{Cd}$ and FLT was conducted by comparing the experimentally observed responses with the toxicity predictions by use of the Bliss independence model (Bliss, 1939). Expected toxicities were obtained (Eq. (2)):

$P_{12}=P_{1}+P_{2}-P_{1} \times P_{2}$

where, $P_{12}(\%)$ denotes predicted combined fractional effect for Cd and FLT in certain concentration (\% decrease or increase from the control); $P_{1}$ and $P_{2}$ denote observed fractional effects evoked from single $\mathrm{Cd}$ and FLT respectively (\% greater or less relative to the control). Antagonistic and synergistic interactions are obtained if the observed data are, respectively, significantly higher and lower than the expected data $\left(P_{12}\right)$. Deviations from predictions for the Bliss independence model were considered to be significant when the predicted data were outside the $95 \%$ confidence limits of the mean observed data.

\section{Results}

\subsection{Germination}

All single and combinational treatments of $\mathrm{Cd}$ and FLT inhibited GR significantly except 1 or $5 \mathrm{mg} \mathrm{FLT/L}(p<$ 0.05) (Table 1). GR was more sensitive to Cd than FLT

Table 1 Effects of Cd and fluoranthene (FLT) on germination vigor (GV) (3 days) and final germination rate (GR) (7 days) of soybean seeds

\begin{tabular}{llll}
\hline $\mathrm{Cd}(\mathrm{mg} / \mathrm{L})$ & FLT $(\mathrm{mg} / \mathrm{L})$ & $\mathrm{GV}(\%)$ & $\mathrm{GR}(\%)$ \\
\hline 0 & $0(1 \% \text { acetone })^{*}$ & $80.00 \pm 0.0667 \mathrm{a}^{* *}$ & $100.00 \pm 0.0667 \mathrm{a}$ \\
0 & 0 & $81.33 \pm 0.0298 \mathrm{a}$ & $98.67 \pm 0.0298 \mathrm{ab}$ \\
& 1 & $66.67 \pm 0.0816 \mathrm{~b}$ & $94.67 \pm 0.0558 \mathrm{ab}$ \\
& 5 & $66.67 \pm 0.0667 \mathrm{~b}$ & $95.56 \pm 0.0385 \mathrm{ab}$ \\
& 10 & $62.67 \pm 0.0365 \mathrm{bc}$ & $92.00 \pm 0.0558 \mathrm{~b}$ \\
5 & 0 & $69.33 \pm 0.0596 \mathrm{~b}$ & $90.67 \pm 0.0596 \mathrm{~b}$ \\
& 1 & $62.67 \pm 0.0365 \mathrm{bc}$ & $89.33 \pm 0.0365 \mathrm{bc}$ \\
& 5 & $61.33 \pm 0.0365 \mathrm{bc}$ & $88.33 \pm 0.0365 \mathrm{bc}$ \\
& 10 & $53.33 \pm 0.0471 \mathrm{c}$ & $82.67 \pm 0.0365 \mathrm{c}$ \\
& 0 & $61.33 \pm 0.0558 \mathrm{bc}$ & $82.67 \pm 0.0760 \mathrm{c}$ \\
& 1 & $53.33 \pm 0.0667 \mathrm{c}$ & $80.00 \pm 0.0667 \mathrm{c}$ \\
& 5 & $49.33 \pm 0.1011 \mathrm{c}$ & $80.00 \pm 0.0667 \mathrm{c}$ \\
15 & 10 & $46.67 \pm 0.0000 \mathrm{~d}$ & $76.67 \pm 0.0471 \mathrm{~cd}$ \\
& 0 & $46.67 \pm 0.0471 \mathrm{~d}$ & $71.67 \pm 0.1000 \mathrm{~d}$ \\
& 1 & $42.67 \pm 0.0365 \mathrm{~d}$ & $69.33 \pm 0.0760 \mathrm{~d}$ \\
& 5 & $41.33 \pm 0.0558 \mathrm{~d}$ & $65.33 \pm 0.0558 \mathrm{~d}$ \\
& 10 & $21.33 \pm 0.0869 \mathrm{e}$ & $48.00 \pm 0.1095 \mathrm{e}$
\end{tabular}

* Solvent control with $1 \%$ acetone.

** Data are represented as mean \pm standard error. The values followed by the same letters do not differ statistically significantly (LSD, $p<0.05$ ). 
and inversely proportional to concentration, whereas GV (3 days) was also sensitive to FLT which indicated that FLT delayed germination of soybean seeds. GR and GV were the lowest $(48.00 \%, 21.33 \%)$ when seeds were exposed to the highest concentrations of pollutants $(15 \mathrm{mg} \mathrm{Cd} / \mathrm{L}+10$ $\mathrm{mg}$ FLT/L). There were significant interactions between $\mathrm{Cd}$ and FLT on GR $\left(r^{2}=0.852, F=2.168, p<0.05\right)$ and $\mathrm{GV}\left(r^{2}=0.884, F=2.356, p<0.05\right)$ of soybean seeds. Based on the analysis of the Bliss independence model, antagonism between Cd and FLT on GR and GV
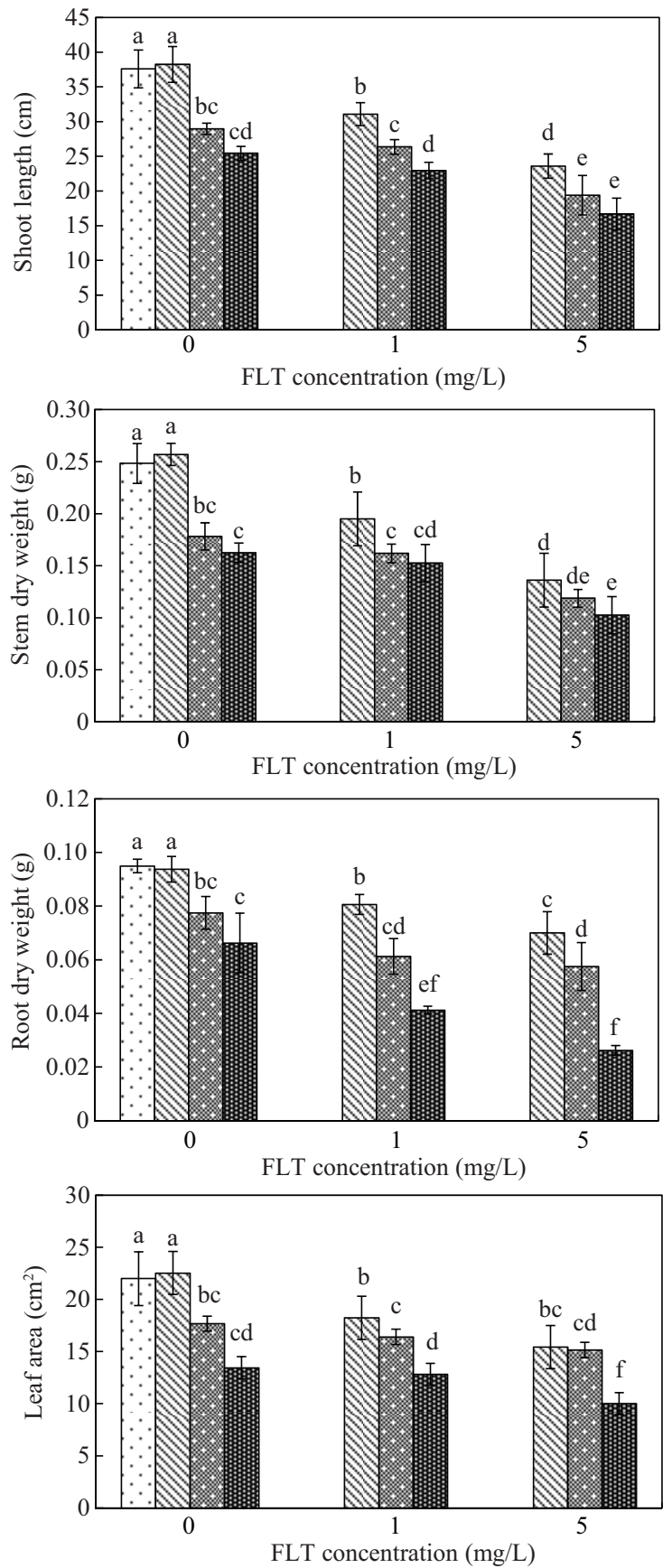

was observed for $5 \mathrm{mg} \mathrm{Cd} / \mathrm{L}+1$ or $5 \mathrm{mg} \mathrm{FLT} / \mathrm{L}, 10 \mathrm{mg}$ $\mathrm{Cd} / \mathrm{L}+1 \mathrm{mg}$ FLT/L, and $15 \mathrm{mg} \mathrm{Cd} / \mathrm{L}+1 \mathrm{mg} \mathrm{FLT} / \mathrm{L}$, but synergism for other combinations except for $15 \mathrm{mg} \mathrm{Cd} / \mathrm{L}$ + $5 \mathrm{mg}$ FLT/L on GV (Table 2).

\subsection{Growth response}

All treatments significantly $(p<0.05)$ delayed growth of soybean seedlings, whereas the extent of delay varied among treatments and among indices of growth (Fig. 1). When soybean seedlings were treated with $5 \mathrm{mg} \mathrm{Cd} / \mathrm{L}$,
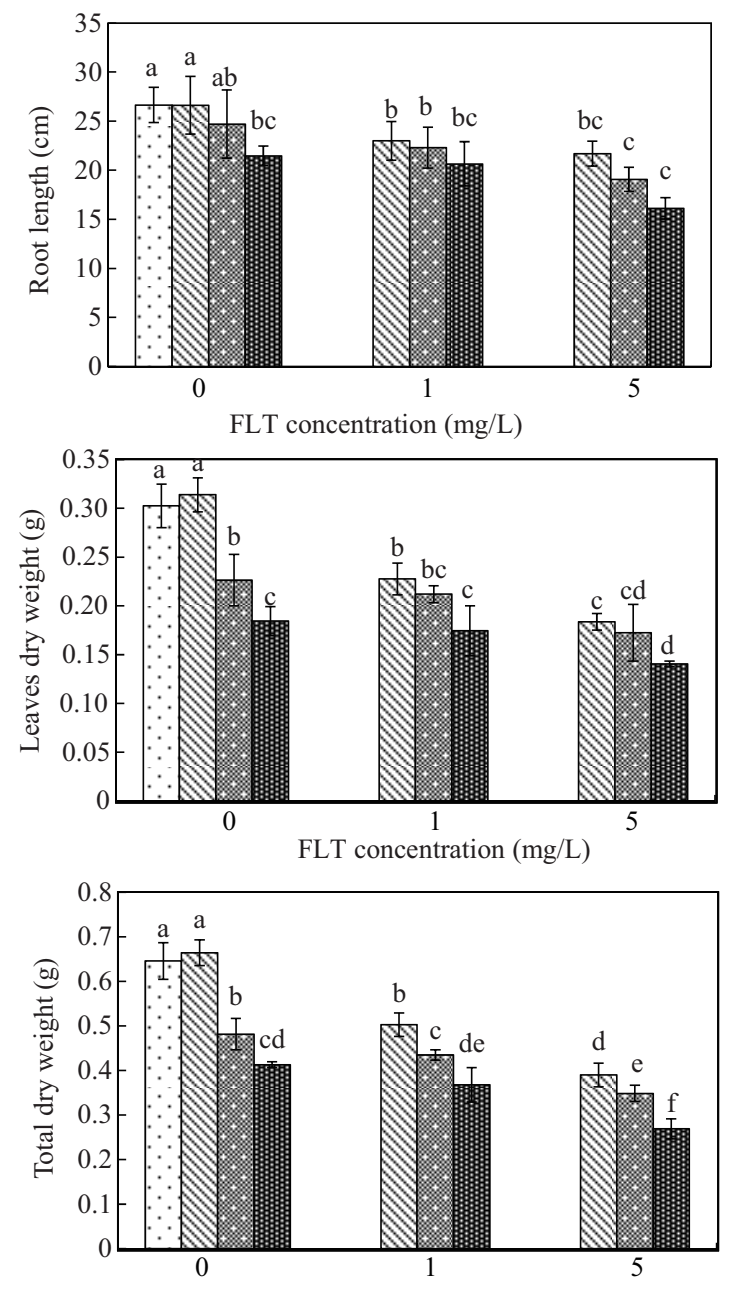

FLT concentration $(\mathrm{mg} / \mathrm{L})$

$\square$ Solvent control ( $1 \%$ actone)

⿶Cd: $0 \mathrm{mg} / \mathrm{L}$

圆 Cd: $5 \mathrm{mg} / \mathrm{L}$

㽗 Cd: $10 \mathrm{mg} / \mathrm{L}$

Fig. 1 Effects of cadmium (Cd) and fluoranthene (FLT) on length of shoot and length of root, stem dry weight, leaves dry weight, root dry weight, total dry weight and leaf area of soybean seedlings. Error bars represent the standard deviation (SD) of four replicates. The values indicated by the same letters do not differ statistically significantly (LSD, $p<0.05)$. 
Table 2 Comparison of predicted and measured responses of GR and GV of soybean seedlings to the exposure of FLT and Cd based on the Bliss independence model

\begin{tabular}{|c|c|c|c|c|c|c|c|}
\hline \multirow{2}{*}{$\mathrm{Cd}(\mathrm{mg} / \mathrm{L})$} & \multirow{2}{*}{ FLT (mg/L) } & \multicolumn{3}{|c|}{ GR } & \multicolumn{3}{|c|}{$\mathrm{GV}$} \\
\hline & & PE $(\%)$ & $\mathrm{OE}(\%)$ & Conclusion* & PE (\%) & $\mathrm{OE}(\%)$ & Conclusion \\
\hline \multirow[t]{3}{*}{5} & 1 & 11.83 & 9.46 & ANT & 30.13 & 22.95 & ANT \\
\hline & 5 & 11.01 & 10.47 & ANT & 30.13 & 24.59 & ANT \\
\hline & 10 & 14.32 & 16.22 & SYN & 34.32 & 34.43 & SYN \\
\hline \multirow[t]{3}{*}{10} & 1 & 19.61 & 18.92 & ANT & 38.19 & 34.43 & ANT \\
\hline & 5 & 18.86 & 18.92 & SYN & 38.19 & 39.34 & SYN \\
\hline & 10 & 21.88 & 22.30 & SYN & 41.90 & 42.62 & SYN \\
\hline \multirow[t]{3}{*}{15} & 1 & 30.31 & 29.73 & ANT & 52.97 & 47.54 & ANT \\
\hline & 5 & 29.66 & 33.78 & SYN & 52.97 & 49.18 & ANT \\
\hline & 10 & 32.27 & 51.35 & SYN & 55.79 & 73.77 & SYN \\
\hline
\end{tabular}

* Predicted effect calculated with Bliss independence model was represented by PE, and observed effect was represented by OE. When OE was greater than PE, antagonism (ANT) (less inhibition than predicted) was recorded; when OE was less than PE (more inhibition than predicted), synergism (SYN) was recorded.

shoot length, root length, leaf dry weight, stem dry weight, root dry weight and leaf area of seedlings were $24.26 \%$, $7.16 \%, 27.89 \%, 30.66 \%, 17.33 \%$ and $21.59 \%$, less than the controls, respectively. The degree of inhibition in these indices of growth of soybean seedlings treated with 10 $\mathrm{mg} \mathrm{Cd} / \mathrm{L}$ were $33.5 \%, 19.32 \%, 41.24 \%, 36.74 \%, 29.33 \%$ and $40.36 \%$ greater than values of controls, respectively. Similarly, growth of soybean seedlings was inhibited more severely by $5 \mathrm{mg}$ FLT/L than $1 \mathrm{mg}$ FLT/L.

Combinations of Cd and FLT (Fig. 1) inhibited growth to a greater extent than either applied individually and the maximum toxicity was observed when both were at the maximum concentration. The results of the two-way ANOVA showed that: shoot length $\left(r^{2}=0.940, F=3.593\right.$, $p<0.05)$, root length $\left(r^{2}=0.703, F=0.701, p>0.05\right)$, leaves dry weight $\left(r^{2}=0.892, F=7.211, p<0.05\right)$ stem dry weight $\left(r^{2}=0.903, F=5.551, p<0.05\right)$, root dry weight $\left(r^{2}=0.910, F=1.896,0.05<p<0.5\right)$, total dry weight $\left(r^{2}=0.955, F=9.791, p<0.05\right)$, leaf area $\left(r^{2}=\right.$ $0.821, F=2.377, p<0.05)$ were all significantly affected. There was a significant interaction between effects of $\mathrm{Cd}$ and FLT on growth of soybean seedlings based on the analysis with the Bliss independence model (Table 3). Antagonistic effects between Cd and FLT on shoot length, stem dry weight, leaves dry weight and leaf area of soybean seedlings were observed. However, synergetic effects between Cd and FLT were observed on root length when exposed to the greatest concentration of FLT, and for root dry weight, the interaction between Cd and FLT was synergistic for all combinations of treatments.

\subsection{Gas exchange parameters}

Net photosynthetic rate $(\mathrm{Pn})$ and stomatal conductance (Gs) were significantly $(p<0.05)$ reduced when plants were exposed to $\mathrm{Cd}$ or FLT, alone or in combination (Fig. 2). The reduction of $\mathrm{Pn}$ and Gs caused by exposure to mixtures of Cd and FLT was greater than that caused by either alone and was the greatest when the concentrations of $\mathrm{Cd}$ and FLT were both at the maximum dose. Intercellular $\mathrm{CO}_{2}$ concentration $\left(C_{\mathrm{i}}\right)$ was higher in leaves of plants exposed to 5 or $10 \mathrm{mg} \mathrm{Cd} / \mathrm{L}$ or $(10 \mathrm{mg} \mathrm{Cd} / \mathrm{L}+$ $1 \mathrm{mg}$ FLT/L), and was lower in other treatments compared with controls. There was a significant interaction between Cd and FLT on Pn $\left(r^{2}=0.947, F=11.296, p<0.05\right)$ and

Table 3 Comparison of predicted and measured responses of shoot length, root length, leaf area and dry weight of soybean seedlings to the exposure of FLT and Cd using Bliss independence model

\begin{tabular}{|c|c|c|c|c|c|c|c|c|c|c|c|c|c|}
\hline \multirow{2}{*}{$\begin{array}{l}\mathrm{Cd} \\
(\mathrm{mg} / \mathrm{L})\end{array}$} & \multirow{2}{*}{$\begin{array}{l}\text { FLT } \\
(\mathrm{mg} / \mathrm{L})\end{array}$} & \multicolumn{3}{|c|}{ Shoot length } & \multicolumn{3}{|c|}{ Root length } & \multicolumn{3}{|c|}{ Leaf area } & \multicolumn{3}{|c|}{ Root dry weight } \\
\hline & & PE $(\%)$ & $\mathrm{OE}(\%)$ & Conclusion * & PE (\%) & $\mathrm{OE}(\%)$ & Conclusion & PE (\%) & $\mathrm{OE}(\%)$ & Conclusion & PE (\%) & $\mathrm{OE}(\%)$ & Conclusion \\
\hline \multirow[t]{2}{*}{5} & 1 & 38.44 & 31.08 & ANT & 19.78 & 16.20 & ANT & 36.54 & 27.24 & ANT & 28.91 & 34.67 & SYN \\
\hline & 5 & 53.26 & 49.29 & ANT & 24.32 & 28.36 & SYN & 46.38 & 32.79 & ANT & 38.28 & 38.67 & SYN \\
\hline \multirow[t]{2}{*}{10} & 1 & 45.95 & 39.98 & ANT & 30.29 & 22.43 & ANT & 51.73 & 43.13 & ANT & 39.23 & 56.00 & SYN \\
\hline & 5 & 58.96 & 56.35 & ANT & 34.23 & 39.47 & SYN & 59.21 & 55.63 & ANT & 47.24 & 72.00 & SYN \\
\hline \multirow{2}{*}{$\begin{array}{l}\mathrm{Cd} \\
(\mathrm{mg} / \mathrm{L})\end{array}$} & \multirow{2}{*}{$\begin{array}{l}\text { FLT } \\
(\mathrm{mg} / \mathrm{L})\end{array}$} & \multicolumn{3}{|c|}{ Stem dry weight } & \multicolumn{3}{|c|}{ Leaves dry weight } & \multicolumn{3}{|c|}{ Total dry weight } & & & \\
\hline & & $\mathrm{PE}(\%)$ & $\mathrm{OE}(\%)$ & Conclusion & PE $(\%)$ & $\mathrm{OE}(\%)$ & Conclusion & PE (\%) & $\mathrm{OE}(\%)$ & Conclusion & & & \\
\hline \multirow[t]{2}{*}{5} & 1 & 47.36 & 36.98 & ANT & 47.71 & 32.47 & ANT & 45.07 & 34.52 & ANT & & & \\
\hline & 5 & 63.22 & 53.77 & ANT & 57.77 & 45.02 & ANT & 57.42 & 47.51 & ANT & & & \\
\hline \multirow[t]{2}{*}{10} & 1 & 51.98 & 40.63 & ANT & 57.39 & 44.42 & ANT & 52.91 & 44.59 & ANT & & & \\
\hline & 5 & 66.45 & 60.10 & ANT & 65.58 & 55.25 & ANT & 63.50 & 59.49 & ANT & & & \\
\hline
\end{tabular}

* Predicted effect calculated with Bliss independence model was represented by PE, and observed effect was represented by OE. When OE was greater than PE, antagonism (ANT) (less inhibition than predicted) was recorded; when OE was less than PE (more inhibition than predicted), synergism (SYN) was recorded. 
$\square 1 \%$ acetone $\square \mathrm{Cd}: 0 \mathrm{mg} / \mathrm{L}$ 娄 Cd: $5 \mathrm{mg} / \mathrm{L}$ 国 $\mathrm{Cd}: 10 \mathrm{mg} / \mathrm{L}$

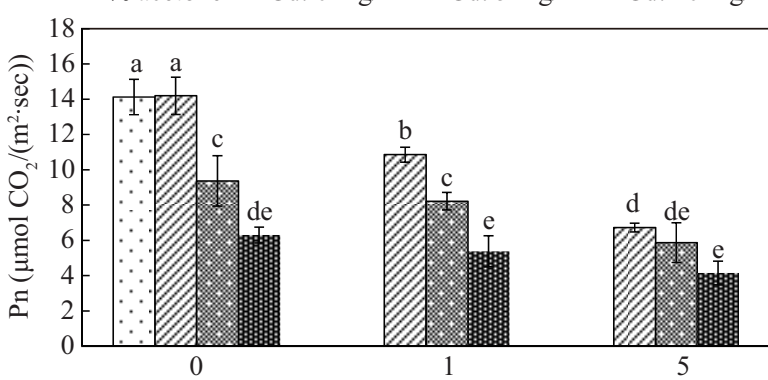

FLT concentration $(\mathrm{mg} / \mathrm{L})$

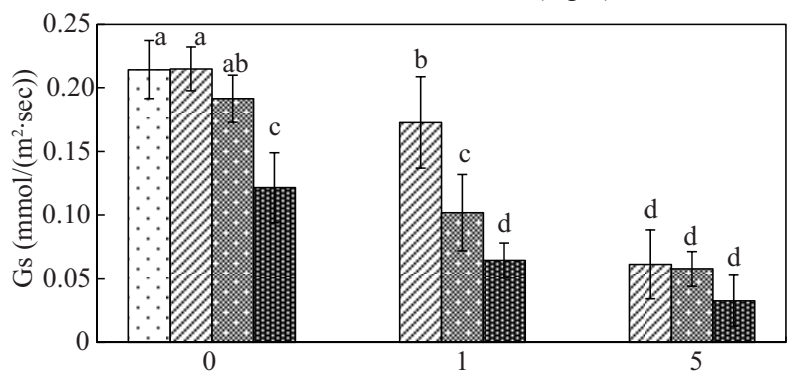

FLT concentration (mg/L)

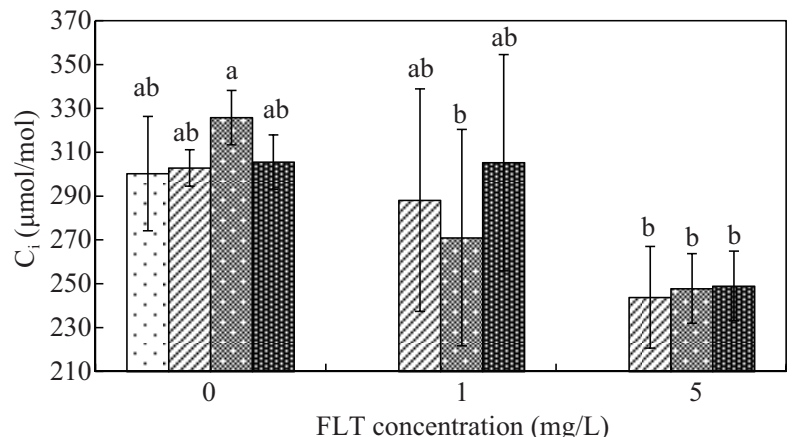

Fig. 2 Effects of Cd and FLT on net photosynthesis rate Pn, stomatal conductance $\mathrm{Gs}$ and intercellular $\mathrm{CO}_{2}$ concentration $C_{\mathrm{i}}$ of soybean seedlings. Error bars represent the standard deviation (SD) of four replicates.

Gs $\left(r^{2}=0.911, F=4.340, p<0.05\right)$, while there was no significant interaction for $C_{\mathrm{i}}\left(r^{2}=0.537, F=0.993,0.05\right.$ $<p<0.5)$. Based on the results of the Bliss independence model, there was an antagonistic effect between $\mathrm{Cd}$ and FLT on Pn of soybean seedlings (Table 4).

\subsection{Chlorophyll content}

Cd and FLT, both singly and jointly resulted in lower contents of Chl- $a$, Chl- $b$ and total Chl, but the magnitude of effect was dependent on combinations of Cd and FLT (Fig. 3). The content of $\mathrm{Chl}$ was inversely proportional to concentrations of Cd or FLT applied individually. Exposure to the lowest concentration of FLT $(1 \mathrm{mg} / \mathrm{L})$ moderated the reduction of $\mathrm{Chl}$ caused by $\mathrm{Cd}$. Chl- $a / \mathrm{Chl}-$ $b$ ratios indicated that Chl- $a$ was more sensitive to $\mathrm{Cd}$ than Chl- $b$. There were significant interactions between effects of Cd and FLT on Chl- $a\left(r^{2}=0.980, F=11.028, p<0.05\right)$, Chl- $b\left(r^{2}=0.909, F=3.985, p<0.05\right)$ and total of them $\left(r^{2}=0.984, F=13.538, p<0.05\right)$. Based on the mediation of FLT on the effect of Cd observed and results of the Bliss independence model, the interaction was antagonistic in most combinations, but synergism when $\mathrm{Cd}$ and FLT were both at the highest concentrations for Chl- $a$ and Chl- $a+b$ (Table 5).

\subsection{Chlorophyll fluorescence}

$F_{\mathrm{v}} / F_{\mathrm{m}}$ and $\varphi_{\text {PSII }}$ of soybeans were inversely proportional to concentrations when exposed individually to Cd or FLT (Fig. 4). The lower $F_{\mathrm{v}} / F_{\mathrm{m}}$ and $\varphi_{\text {PSII }}$ values caused by $\mathrm{Cd}$ alone reached significant level $(p<0.05)$, whereas the lower values caused by exposure to FLT was not significant $(p<0.05)$. The opposite effect was also observed in $F_{0}$ of soybean seedlings.

There was a significant interaction between effects of $\mathrm{Cd}$ and FLT on fluorescence parameters of soybean seedlings: $F_{0}\left(r^{2}=0.987, F=64.816, p<0.01\right), F_{\mathrm{v}} / F_{\mathrm{m}}\left(r^{2}=0.896\right.$, $F=2.757, p<0.05)$ and $\varphi_{\text {PSII }}\left(r^{2}=0.802, F=2.735\right.$, $p<0.05)$. Based on the Bliss independence model, the interaction between effects of Cd and FLT on chlorophyll fluorescence was antagonistic (Table 4). To understand the relationship between $\mathrm{Pn}$, and chlorophyll content and $F_{0}$, $F_{\mathrm{v}} / F_{\mathrm{m}}$ and $\varphi_{\text {PSII }}$ in soybean seedlings exposed to $\mathrm{Cd}$ and FLT, correlation coefficients between Pn and other indices were calculated. Coefficients of determination $\left(r^{2}\right)$ and predictive, general linear models for Pn and chlorophyll content $\left(F_{0}, F_{\mathrm{v}} / F_{\mathrm{m}}\right.$ and $\left.\varphi_{\text {PSII }}\right)$ were: $y=8.287 x-3.371, r^{2}$ $=0.617, p<0.01 ; y=-0.273 x+50.607, r^{2}=0.841, p<$ $0.001 ; y=226.223 x-172.890, r^{2}=0.846, p<0.001 ; y=$ $87.977 x-8.013, r^{2}=0.882, p<0.001$. Pn was negatively related to $F_{0}$ and positively related to chlorophyll content, $F_{\mathrm{v}} / F_{\mathrm{m}}$ and $\varphi$ PSII.

Table 4 Comparison of predicted and measured responses of net photosynthesis rate (Pn) and chlorophyll fluorescence parameters $\left(F_{0}, F_{\mathrm{v}} / F_{\mathrm{m}}, \varphi_{\text {PSII }}\right)$ of soybean seedlings using Bliss independence models for the exposure of FLT and Cd

\begin{tabular}{|c|c|c|c|c|c|c|c|c|c|c|c|c|c|}
\hline \multirow{2}{*}{$\begin{array}{l}\mathrm{Cd} \\
(\mathrm{mg} / \mathrm{L})\end{array}$} & \multirow{2}{*}{$\begin{array}{l}\mathrm{FLT} \\
(\mathrm{mg} / \mathrm{L})\end{array}$} & \multicolumn{3}{|c|}{ Pn } & \multicolumn{3}{|c|}{$F_{0}$} & \multicolumn{3}{|c|}{$F_{\mathrm{v}} / F_{\mathrm{m}}$} & \multicolumn{3}{|c|}{$\varphi_{\text {PSII }}$} \\
\hline & & PE (\%) & $\mathrm{OE}(\%)$ & Conclusion* & PE (\%) & OE (\%) & Conclusion & PE (\%) & $\mathrm{OE}(\%)$ & Conclusion & PE (\%) & $\mathrm{OE}(\%)$ & Conclusion \\
\hline \multirow[t]{2}{*}{5} & 1 & 49.47 & 42.05 & ANT & 20.70 & 10.64 & ANT & 3.98 & 2.40 & ANT & 36.16 & 20.72 & ANT \\
\hline & 5 & 68.68 & 58.60 & ANT & 23.86 & 13.52 & ANT & 4.83 & 3.26 & ANT & 40.57 & 36.79 & ANT \\
\hline \multirow[t]{2}{*}{10} & 1 & 66.00 & 62.09 & ANT & 30.50 & 20.54 & ANT & 5.43 & 3.81 & ANT & 45.30 & 27.35 & ANT \\
\hline & 5 & 78.93 & 70.73 & ANT & 33.27 & 24.91 & ANT & 6.27 & 5.68 & ANT & 49.07 & 49.02 & ANT \\
\hline
\end{tabular}

* Predicted effect calculated with Bliss independence model was represented by PE, and observed effect was represented by OE. When OE was greater than PE, antagonism (ANT) (less inhibition than predicted) was recorded; when OE was less than PE (more inhibition than predicted), synergism (SYN) was recorded. 
Table 5 Comparison of predicted and measured responses of chlorophyll (Chl) content of soybean seedlings using Bliss independence models for the exposure of FLT and Cd

\begin{tabular}{|c|c|c|c|c|c|c|c|c|c|c|}
\hline \multirow{2}{*}{$\begin{array}{l}\mathrm{Cd} \\
(\mathrm{mg} / \mathrm{L})\end{array}$} & \multirow{2}{*}{$\begin{array}{l}\text { FLT } \\
(\mathrm{mg} / \mathrm{L})\end{array}$} & \multicolumn{3}{|c|}{ Chl- $a$} & \multicolumn{3}{|c|}{ Chl- $b$} & \multicolumn{3}{|c|}{ Chl- $a+b$} \\
\hline & & $\begin{array}{l}\mathrm{PE}(\%) \\
(\%)\end{array}$ & $\begin{array}{l}\mathrm{OE}(\%) \\
(\%)\end{array}$ & Conclusion* & $\begin{array}{l}\mathrm{PE}(\%) \\
(\%)\end{array}$ & $\begin{array}{l}\mathrm{OE}(\%) \\
(\%)\end{array}$ & Conclusion & $(\%)$ & $(\%)$ & \\
\hline \multirow[t]{2}{*}{5} & 1 & 34.30 & 10.74 & ANT & 28.33 & 15.52 & ANT & 32.68 & 12.01 & ANT \\
\hline & 5 & 39.55 & 32.88 & ANT & 40.18 & 20.10 & ANT & 39.56 & 29.48 & ANT \\
\hline \multirow[t]{2}{*}{10} & 1 & 47.83 & 21.50 & ANT & 36.88 & 19.82 & ANT & 44.87 & 21.05 & ANT \\
\hline & 5 & 52.00 & 60.49 & SYN & 47.33 & 38.56 & ANT & 50.51 & 54.66 & SYN \\
\hline
\end{tabular}

${ }^{*}$ Predicted effect calculated with Bliss independence model was represented by PE, and observed effect was represented by OE. When OE was greater than PE, antagonism (ANT) (less inhibition than predicted) was recorded; when OE was less than PE (more inhibition than predicted), synergism (SYN) was recorded.

Solvent control (1\% actone) $\mathbb{Q} \mathrm{Cd}: 0 \mathrm{mg} / \mathrm{L} \quad$ 圆 $\mathrm{Cd}: 5 \mathrm{mg} / \mathrm{L} \quad \mathrm{Cd}: 10 \mathrm{mg} / \mathrm{L}$
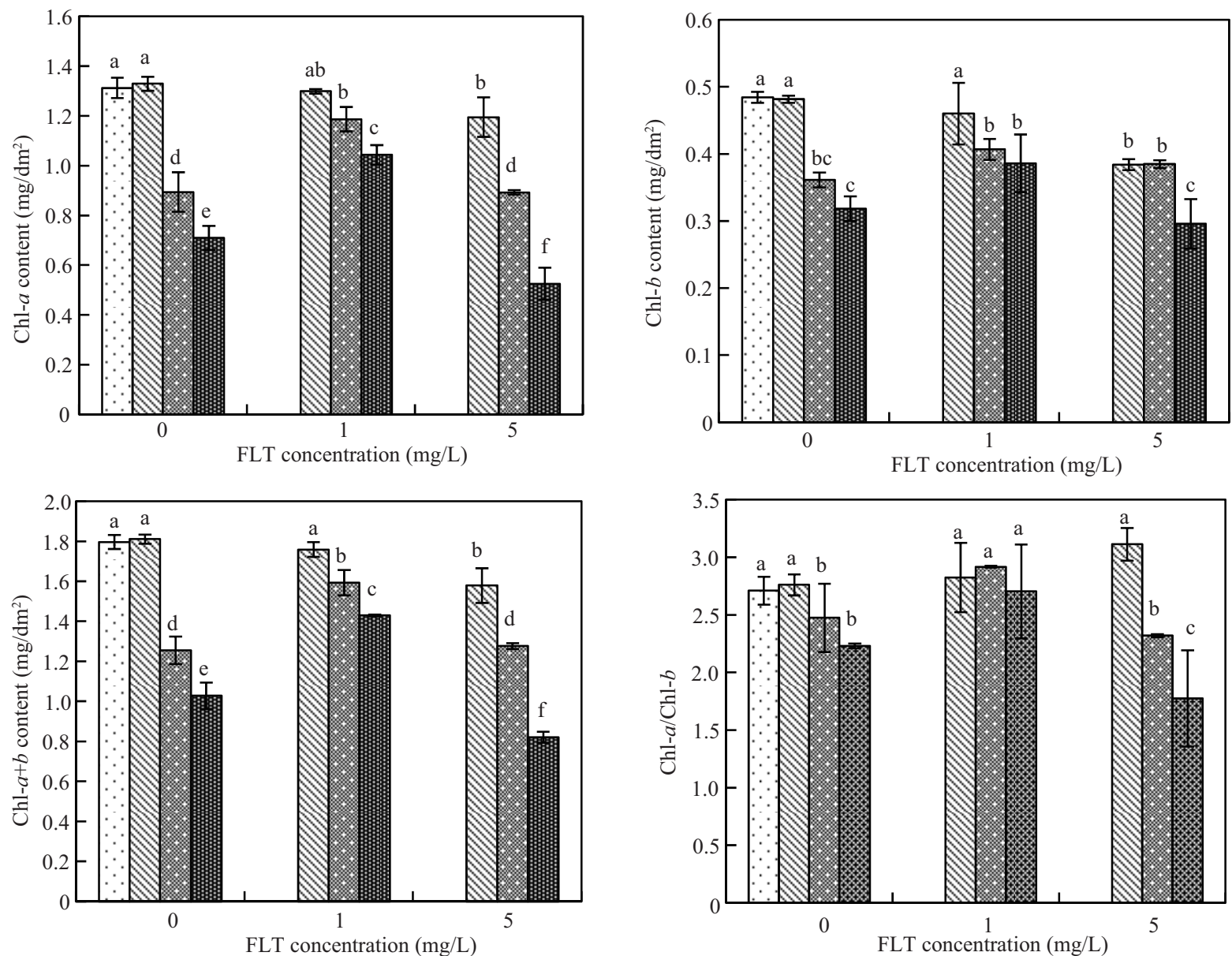

Fig. 3 Effects of Cd and FLT on content of chlorophyll $a$, chlorophyll $b$, total content of chlorophyll and the ratio of content of chlorophyll $a$ and chlorophyll $b$ in soybean seedlings. Error bars represent the standard deviation (SD) of four replicates The values indicated by the same letter do not differ statistically significantly (LSD, $p<0.05)$.

\section{Discussion}

Germination of seeds is one of the most sensitive processes in plants, inhibition of which is among toxic effects of transition metals and PAHs (Ernst, 1998; Henner et al., 1999). Cadmium, after penetrating into seeds, cannot only affect mineral nutrient transport and sugar mobilization from the cotyledon to growing embryonic axis, but also disrupt germination by causing solute losses into the medi- um (Rahoui et al., 2008; Sfaxi-Bousbih et al., 2010). The mechanism by which FLT affects germination is not clear. One possible reason is that gibberellic acid is inhibited by FLT in endosperm (Kummerová and Kmentová, 2004). In the present study, the potential of $\mathrm{Cd}$ and FLT for inhibiting germination of soybean seeds were different. The toxicity of Cd observed in this study was similar to those found by other researchers for soybean (Liu et al., 2011), pea (Chugh and Sawhney, 1996) and other bean 


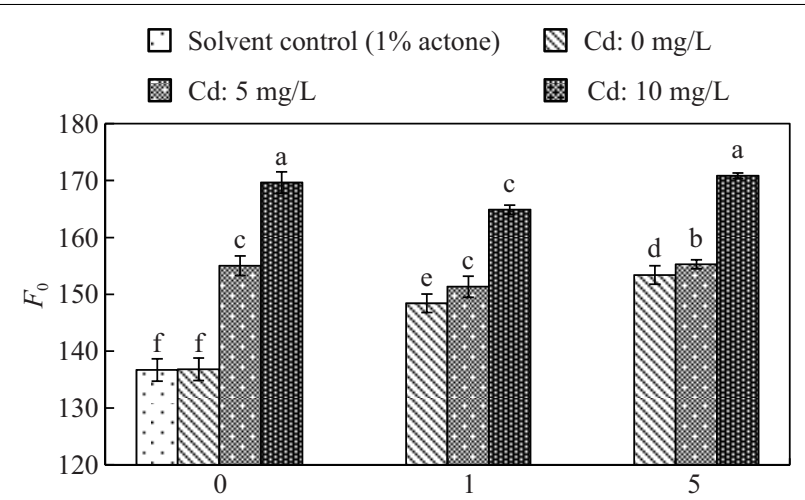

FLT concentration $(\mathrm{mg} / \mathrm{L})$
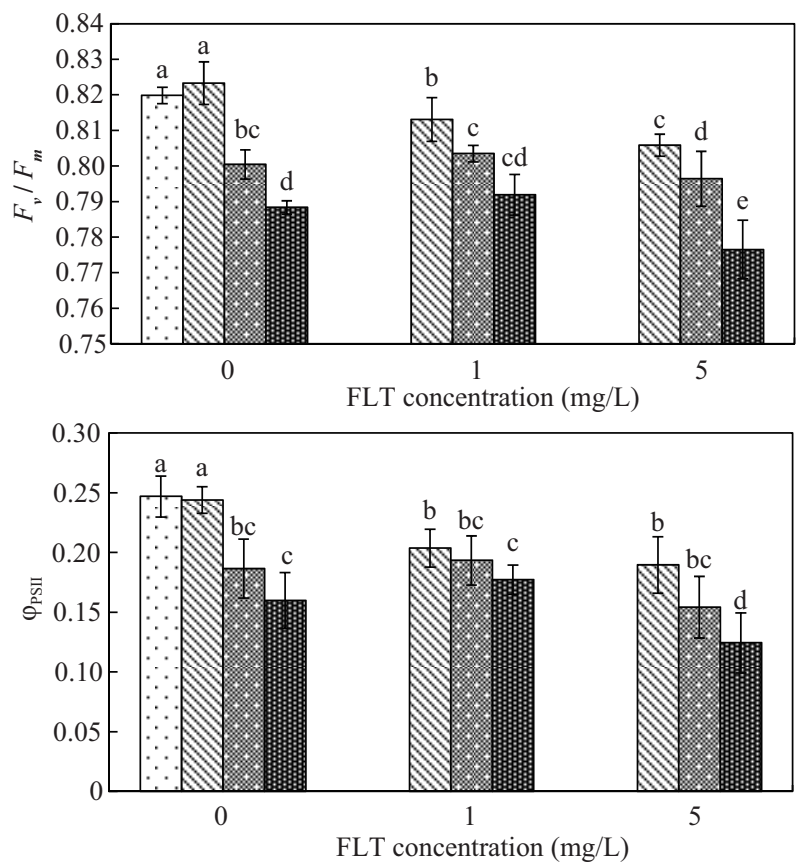

Fig. 4 Effects of cadmium (Cd) and fluoranthene (FLT) on the initial fluorescence $F_{0}$, the maximum quantum efficiency of PSII photochemistry $F_{\mathrm{v}} / F_{\mathrm{m}}$, and PSII operating efficiency $\varphi_{\mathrm{PSII}}$ of soybean seedlings. Error bars represent the standard deviation (SD) of four replicates.

species (Rahoui et al., 2008; Sfaxi-Bousbih et al., 2010). Exposures to FLT alone at concentrations lower than 10 $\mathrm{mg} / \mathrm{L}$ did not result in significantly lower germination rate (7 days), but all concentrations of FLT alone resulted in significant reduction of germination vigor (3 days), indicating that FLT delayed germination of soybean seeds, as compared to controls. The result is consistent with those of previous studies on effects of FLT on pea, maize, lettuce, tomato and other species (Henner et al., 1999; Kummerová and Kmentová, 2004; Smith et al., 2006).

Indices of growth such as plant height, biomass and leaf area are a function of growth of plants. The observations in the current study, that both Cd and FLT reduced shoot length, root length, leaves dry weight, stem dry weight, root dry weight and leaf area of soybean seedlings. Similar results were obtained in soybean (Ghorbanli et al., 2000), rice (Moya et al., 1993) and garlic (Liu et al., 2003) stressed by cadmium. Inhibition of growth by FLT and other PAHs was also observed in previous studies (Kummerova and Kmentova, 2004; Váňová et al., 2009; Oguntimehin et al., 2010; Kummerová et al., 2013). Owing to its highly lipophilic nature, FLT can interact with biological membranes leading to changes in their structure and function, which, in turn, could impair growth and metabolic activity of cells (Sikkema et al., 1994). Due to its affinity to sulfhydryl groups, Cd can block essential functional group in biomolecules, which can result in lower efficiency of enzymes activity in various metabolic processes, such as photosynthesis, respiration, nutrient elements assimilation and transport (Ferreira et al., 2002; Draži et al., 2004; Lee et al., 2006). Among the metabolic processes mentioned above, photosynthesis, as a central anabolic pathway providing energy-rich organic compounds, is very important to plant growth (Buchanan et al., 2000). Inhibition of any component of the photosynthetic apparatus will adversely affect physiological activities, and likely plant growth (Baek et al., 2004; Cuypers et al., 2010). Gas exchange parameters such as net photosynthetic rate $(\mathrm{Pn})$, stomatal conductance (Gs) and intercellular $\mathrm{CO}_{2}$ concentration $\left(C_{\mathrm{i}}\right)$ represent photosynthetic capacity, and thereby are often used to determine the influence of stresses on photosynthesis. Both $\mathrm{Cd}$ and FLT did result in inhibition of photosynthesis, which is consistent with the results observed in other studies (Moya et al., 1993; Váňová et al., 2009; Oguntimehin et al., 2010). A lower $G_{\mathrm{s}}$ value might be a consequence of stomatal closure, which is an important stress avoidance mechanism in plants (Poschenrieder et al., 1989). Higher or lower $C_{\mathrm{i}}$ levels caused by $\mathrm{Cd}$ and FLT suggest that both stomatal and non-stomatal factors were responsible for the reduction in Pn.

Both impairment of PSII and PSI and loss of activities of enzymes in the Calvin-cycle caused by Cd and FLT might be involved in the decline of $\mathrm{CO}_{2}$ assimilation capacity and thereby decrease Pn. It has been suggested that the photosynthetic utilization of light by Thlaspi caerulescens is more sensitive to $\mathrm{Cd}$ than is the Calvin Cycle (Küpper et al., 2002). Thus, to determine the capacity of utilization of absorbed light energy, contents and fluorescence of Chl were determined in the current study (Kummerová and Vanová, 2007).

Like most abiotic stress factors, chloroplasts are the first target affected by Cd and FLT. In the current study, the contents of Chl- $a$ and Chl- $b$ were significantly reduced due to exposure to either Cd or FLT and Chl- $a$ was more sensitive to the effects of Cd stress than Chl- $b$. These results are consistent with previous reports (Huang et al., 1997; Váňová et al., 2009; Ahammed et al., 2012). It has been reported that $\mathrm{Cd}$ inhibited production of chlorophyll by obstructing the formation of the protochlorophyllide reductase ternary complex and synthesis of 5-aminolaevulinic acid (Huang et al., 1997). Fluoranthene or its photolysis products can generate reactive oxygen species inside plant cells, and 
thereby initiate lipid peroxidation (Oguntimehin et al., 2010), but it is not clear now whether the reduction of Chl$a$ and Chl- $b$ is due to their destruction or reduction of their synthesis.

Among the parameters used to describe fluorescence of chl, initial fluorescence of $\mathrm{Chl}\left(F_{0}\right)$, potential yield of photochemical reactions in PSII $\left(F_{\mathrm{v}} / F_{\mathrm{m}}\right)$, and effective quantum yield of PSII ( $\varphi_{\text {PSII }}$ ) are used most frequently in studying the stress physiology of plants (Krause and Weis, 1991; Marwood et al., 2001; Mallick and Mohn, 2003; Kummerová and Vanová, 2007). In the present study, $F_{0}$ was greater when soybeans were exposed to $\mathrm{Cd}$ or FLT. It has been reported that $\mathrm{Cd}$ can inhibit the flow of photosynthetic electrons, destroy the antennae pigments, inhibit the water-splitting complex of the oxidizing site of PSII, down-regulate PSII proteins, as well as competitively bind to the essential $\mathrm{Ca}^{2+}$ site in PSII (Geiken et al., 1998; Mallick and Mohn, 2003; Faller et al., 2005). While mechanisms responsible for greater $F_{0}$ caused by FLT are not known, there are several possible hypotheses. They include: (1) Phosphorylation of the light harvesting complexes (LHCs) and their detachment from the core of PSII, which would lead to a reduced efficiency of energy transfer from LHCs to the reaction center of PSII and thereby cause an increase in $F_{0}$ (Krause and Weis, 1991); (2) The effect of FLT on thylakoid membranes might cause reversible inactivation of PSII (Huang et al., 1997); (3) Destruction of photosynthetic pigment molecules might also cause greater $F_{0}$ (Gensemer et al., 1996); (4) FLT and especially products of its transformation could injure the primary electron donor (Tyr Z) (Kummerová et al., 2006).

The $F_{\mathrm{v}} / F_{\mathrm{m}}$ ratio, which is an indicator of potential efficiency of the primary photochemical reactions in PSII, and $\varphi_{\text {PSII }}$, which is a measure of quantum efficiency were both lower in the presence of Cd or FLT. Because PSII is the first step in photosynthetic electron transport, inhibition of electron transport anywhere within the electron transport chain exerts excitation pressure on PSII. Changes in PSII and $\varphi_{\text {PSII }}$ indicate a greater proportion of inactive PSII reaction centers due to inhibition of photochemical processes of photosynthesis related to electron transport chain in the thylakoid membrane, such as oxidation or degradation of D1 proteins, impairment of PSI leading block of the downstream electron transport, and severely reduced pigment concentrations in reaction centers (Anderson et al., 1997; Huang et al., 1997; Marwood et al., 2001). The results of the current study indicated that exposure to Cd or FLT resulted in less absorption of light energy, electron transport, conversion of light energy and photo phosphorylation in soybean seedlings. These effects on these photosynthetic light reaction processes led to the inhibition of the photosynthesis in soybean seedlings. This mechanism was verified by linear regression which demonstrated that $\mathrm{Pn}$ was negatively related to $F_{0}$ and positively related to chlorophyll content, $F_{\mathrm{v}} / F_{\mathrm{m}}$ and $\varphi_{\mathrm{PSII}}$.
These results are in agreement with previous reports on effects of treatment with Cd or FLT on photosynthetic light reactions of soybean and other plants (Moya et al., 1993; Ghorbanli et al., 2000; Oguntimehin et al., 2010; Ahammed et al., 2012).

In previous studies, both antagonistic and synergistic effects of metals and PAHs on higher plants have been reported. For instance, PAHs modulated toxicity of $\mathrm{Cd}$ in soil to an emergent wetland species (Zhang et al., 2011), but pyrene combined with $\mathrm{Cd}$ did not alleviate toxicity to Zea mays in soil (Zhang et al., 2009). Fluoranthene in solution resulted in less accumulation of $\mathrm{Cu}$ and $\mathrm{Pb}$ by wheat (Wetzel et al., 1994). Cr and benzo(a)pyrene in solution have significant antagonistic effects on the germination rate of ryegrass, and exhibit several types of interaction for growth of ryegrass with different combinations of concentrations of these two pollutants (Chigbo and Batty, 2013). As and phenanthrene in soil have synergistic effects on antioxidants in Chinese brake (Sun et al., 2011). In summary, these results suggest that combinations of metal and PAHs can exert either antagonistic or synergistic effects, depending on medium, species, growth stages, concentrations and characteristics of pollutants.

\section{Conclusions}

Germination, growth and photosynthesis of soybean seedlings were all inhibited by exposure to $\mathrm{Cd}$ or FLT individually or in combination, and there were significant interactions between both toxicants. Exposure to $\mathrm{Cd}$ and FLT simultaneously had greater effect on germination, growth and photosynthesis of soybean seedlings. Simultaneous exposure to $\mathrm{Cd}$ and FLT resulted in antagonism relative to effects on germination at a concentration of (1 mg FLT/L), whereas the interaction was synergistic when concentrations of FLT and $\mathrm{Cd}$ were higher. The type of interactive effect between 5 or $10 \mathrm{mg} \mathrm{Cd} / \mathrm{L}$ and 1 or $5 \mathrm{mg} \mathrm{FLT/L} \mathrm{on} \mathrm{shoot} \mathrm{growth} \mathrm{and} \mathrm{photosynthesis} \mathrm{of}$ soybean seedlings was mainly antagonism, whereas for root growth, the antagonism and synergism were both observed.

\section{Acknowledgments}

This work was supported by the National Natural Science Foundation of China (No. 41071355, 41171394) and the National International Cooperation Program of China (No. 2012DFA91150). Prof. Giesy was supported by the Einstein Professorship Program of the Chinese Academy of Sciences, and the Canada Research Chair Program.

\section{References}

Ahammed G J, Yuan H L, Ogweno J O, Zhou Y H, Xia X J, Mao W H et al., 2012. Brassinosteroid alleviates phenanthrene and pyrene phytotoxicity by increasing detoxification ac- 
tivity and photosynthesis in tomato. Chemosphere, 86(5): 546-555.

Anderson J M, Park Y I, Chow W S, 1997. Photoinactivation and photoprotection of photosystem II in nature. Physiologia Plantarum, 100(2): 214-223.

Baek K H, Kim H S, Oh H M, Yoon B D, Kim J, Lee I S, 2004. Effects of crude oil, oil components, and bioremediation on plant growth. Journal of Environmental Science and Health, Part A, 39(9): 2465-2472.

Bliss C I, 1939. The toxicity of poisons applied jointly. Annals of Applied Biology, 26(3): 585-615.

Bryselbout C, Henner P, Carsignol J, Lichtfouse É, 2000. Polycyclic aromatic hydrocarbons in highway plants and soils. Evidence for a local distillation effect. Analusis, 28(4): 290293.

Buchanan B B, Gruissem W, Jones R L, 2000. Biochemistry and Molecular Biology of Plants. American Society of Plant Physiologists, Waldorf.

Chigbo C, Batty L, 2013. Effect of combined pollution of chromium and benzo(a)pyrene on seed growth of Lolium perenne. Chemosphere, 90(2): 164-169.

Chugh L K, Sawhney S K, 1996. Effect of cadmium on germination, amylases and rate of respiration of germinating pea seeds. Environmental Pollution, 92(1): 1-5.

Cuypers A, Smeets K, Vangronsveld J, 2010. Heavy metal stress in plants. In: Plant Stress Biology: From Genomics to Systems Biology (Hirt H, ed.). Wiley-VCH Verlag $\mathrm{GmbH}$ and Co. KGaA, Weinheim. 161-178.

Draži G, Mihailovi N, Stojanovi Z, 2004. Cadmium toxicity: the effect on macro- and micro-nutrient contents in soybean seedlings. Biologia Plantarum, 48(4): 605-607.

Ernst W H O, 1998. Effects of heavy metals in plants at the cellular and organismic level ecotoxicology. In: Bioaccumulation and Biological Effects of Chemicals (Gerrit S, Bernd M, eds.). Wiley and Spektrum Akademischer Verlag, Heidelberg. 587-620.

Faller P, Kienzler K, Krieger-Liszkay A, 2005. Mechanism of $\mathrm{Cd}^{2+}$ toxicity: $\mathrm{Cd}^{2+}$ inhibits photoactivation of Photosystem II by competitive binding to the essential $\mathrm{Ca}^{2+}$ site. Biochimica et Biophysica Acta (BBA)-Bioenergetics, 1706(1-2): 158-164.

Farquhar G D, Caemmerer S, Berry J A, 1980. A biochemical model of photosynthetic $\mathrm{CO}_{2}$ assimilation in leaves of $\mathrm{C}_{3}$ species. Planta, 149(1): 78-90.

Ferreira R R, Fornazier R F, Vitória A P, Lea P J, Azevedo R A, 2002. Changes in antioxidant enzyme activities in soybean under cadmium stress. Journal of Plant Nutrition, 25(2): 327-342.

Finger-Teixeira A, de Lucio Ferrarese M L, Ricardo Soares A, da Silva D, Ferrarese-Filho O, 2010. Cadmium-induced lignification restricts soybean root growth. Ecotoxicology and Environmental Safety, 73(8): 1959-1964.

Geiken B, MasojÍdek J, Rizzuto M, Pompili M L, Giardi M T, 1998. Incorporation of [35S]methionine in higher plants reveals that stimulation of the D1 reaction centre II protein turnover accompanies tolerance to heavy metal stress. Plant, Cell and Environment, 21(12): 1265-1273.

Gensemer R W, Ren L, Day K E, Solomon K R, Greenberg B $\mathrm{M}, 1996$. Fluorescence induction as a biomarker of creosote phototoxicity to the aquatic macrophyte Lemna gibba.
In: Environmental Toxicology and Risk Assessment: 5th Volume, ASTM STP 1306 (Bengston D, Henshel D S, eds.). American Society for Testing and Materials, Philadelphia. 163-176.

Genty B, Briantais J M, Baker N R, 1989. The relationship between the quantum yield of photosynthetic electron transport and quenching of chlorophyll fluorescence. Biochimica et Biophysica Acta (BBA)-General Subjects, 990(1): 87-92.

Ghorbanli M, Kaveh S H, Sepehr M F, 2000. Effects of cadmium and gibberellin on growth and photosynthesis of Glycine max. Photosynthetica, 37(4): 627-631.

Henner P, Schiavon M, Druelle V, Lichtfouse E, 1999. Phytotoxicity of ancient gaswork soils. Effect of polycyclic aromatic hydrocarbons (PAHs) on plant germination. Organic Geochemistry, 30(8Part 2): 963-969.

Hoagland D R, Arnon D I, 1950. The Water-Culture Method for Growing Plants Without Soil (2nd ed.). California Agricultural Experiment Station, Circular. 347.

Huang X D, McConkey B J, Babu T S, Greenberg B M, 1997. Mechanisms of photoinduced toxicity of photomodified anthracene to plants: Inhibition of photosynthesis in the aquatic higher plant Lemna gibba (duckweed). Environmental Toxicology and Chemistry, 16(8): 1707-1715.

Könemann W H, Pieters M N, 1996. Confusion of concepts in mixture toxicology. Food and Chemical Toxicology, 34(1112): $1025-1031$

Küpper H, Šetlík I, Spiller M, Küpper F C, Prášil O, 2002. Heavy metal-induced inhibition of photosynthesis: targets of in vivo heavy metal chlorophyll formation. Journal of Phycology, 38(3): 429-441.

Krause G H, Weis E, 1991. Chlorophyll fluorescence and photosynthesis: The basics. Annual Review of Plant Physiology and Plant Molecular Biology, 42(1): 313-349.

Kummerová M, Barták M, Dubová J, Tř’ıska J, Zubrová E, Zezulka Š, 2006a. Inhibitory effect of fluoranthene on photosynthetic processes in lichens detected by chlorophyll fluorescence. Ecotoxicology, 15(2): 121-131.

Kummerová M, Krulová J, Zezulka Š, Tř’ıska J, 2006b. Evaluation of fluoranthene phytotoxicity in pea plants by Hill reaction and chlorophyll fluorescence. Chemosphere, 65(3): 489-496.

Kummerová M, Vanova L, 2007. Chlorophyll fluorescence as an indicator of fluoranthene phototoxicity. Plant Soil and Environment, 53(10): 430-436.

Kummerová M, Zezulka Š, Babula P, Váňová L, 2013. Root response in Pisum sativum and Zea mays under fluoranthene stress: Morphological and anatomical traits. Chemosphere, 90(2): 665-673.

Kummerová M, Kmentová E, 2004. Photoinduced toxicity of fluoranthene on germination and early development of plant seedling. Chemosphere, 56(4): 387-393.

Lee K C, Cunningham B A, Paulsen G M, Liang G H, Moore R $\mathrm{B}, 2006$. Effects of cadmium on respiration rate and activities of several enzymes in soybean seedlings. Physiologia Plantarum, 36(1): 4-6.

Lichtenthaler H K, 1987. Chlorophylls and carotenoids: Pigments of photosynthetic biomembranes. In: Methods in Enzymology (Lester Packer R D, ed.). Academic Press, San Diego. 350-382.

Liu D, Jiang W, Gao X, 2003. Effects of cadmium on root growth, 
cell division and nucleoli in root tip cells of garlic. Biologia Plantarum, 47(1): 79-83.

Liu T T, Wu P, Wang L H, Zhou Q, 2011. Response of soybean seed germination to cadmium and acid rain. Biological Trace Element Research, 144(1-3): 1186-1196.

Loewe S, Muischnek H, 1926. Effect of combinations: mathematical basis of problem. Archiv für Experimentelle Pathologie und Pharmakologie, 114: 313-326.

Maliszewska-Kordybach B, Smreczak B, Klimkowicz-Pawlas A, 2009. Concentrations, sources, and spatial distribution of individual polycyclic aromatic hydrocarbons (PAHs) in agricultural soils in the Eastern part of the EU: Poland as a case study. Science of the Total Environment, 407(12): 3746-3753.

Mallick N, Mohn F H, 2003. Use of chlorophyll fluorescence in metal-stress research: a case study with the green microalga Scenedesmus. Ecotoxicology and Environmental Safety, 55(1): 64-69.

Marwood C A, Solomon K R, Greenberg B M, 2001. Chlorophyll fluorescence as a bioindicator of effects on growth in aquatic macrophytes from mixtures of polycyclic aromatic hydrocarbons. Environmental Toxicology and Chemistry, 20(4): 890-898.

Moya J L, Ros R, Picazo I, 1993. Influence of cadmium and nickel on growth, net photosynthesis and carbohydrate distribution in rice plants. Photosynthesis Research, 36(2): 75-80.

Nam J J, Thomas G O, Jaward F M, Steinnes E, Gustafsson O, Jones K C, 2008. PAHs in background soils from Western Europe: Influence of atmospheric deposition and soil organic matter. Chemosphere, 70(9): 1596-1602.

Oguntimehin I, Eissa F, Sakugawa H, 2010. Negative effects of fluoranthene on the ecophysiology of tomato plants ( $L y$ copersicon esculentum Mill): Fluoranthene mists negatively affected tomato plants. Chemosphere, 78(7): 877-884.

Poschenrieder C, Gunsé B, Barceló J, 1989. Influence of cadmium on water relations, stomatal resistance, and abscisic acid content in expanding bean leaves. Plant Physiology, 90(4): $1365-1371$.

Rahoui S, Chaoui A, Ferjani E E, 2008. Differential sensitivity to cadmium in germinating seeds of three cultivars of faba bean (Vicia faba L.). Acta Physiologiae Plantarum, 30(4): 451-456.

Sfaxi-Bousbih A, Chaoui A, El Ferjani E, 2010. Cadmium impairs mineral and carbohydrate mobilization during the germination of bean seeds. Ecotoxicology and Environmental Safety, 73(6): 1123-1129.
Sikkema J, De Bont J, Poolman B, 1994. Interactions of cyclic hydrocarbons with biological membranes. Journal of Biological Chemistry, 269(11): 8022-8028.

Smith M J, Flowers T H, Duncan H J, Alder J, 2006. Effects of polycyclic aromatic hydrocarbons on germination and subsequent growth of grasses and legumes in freshly contaminated soil and soil with aged PAHs residues. Environmental Pollution, 141(3): 519-525.

Sun L, Yan X L, Liao X Y, Wen Y, Chong Z Y, Liang T, 2011a. Interactions of arsenic and phenanthrene on their uptake and antioxidative response in Pteris vittata L. Environmental Pollution, 159(12): 3398-3405.

Sun Y B, Zhou Q X, Xu Y M, Wang L, Liang X F, 2011b. Phytoremediation for co-contaminated soils of benzo[a]pyrene $(\mathrm{B}[\mathrm{a}] \mathrm{P})$ and heavy metals using ornamental plant Tagetes patula. Journal of Hazardous Materials, 186(2-3): 20752082.

Tao S, Cui Y H, Xu F L, Li B G, Cao J, Liu W X et al., 2004. Polycyclic aromatic hydrocarbons (PAHs) in agricultural soil and vegetables from Tianjin. The Science of the Total Environment, 320(1): 11-24.

Váňová L, Kummerová M, Klemš M, Zezulka $\check{S}$, 2009. Fluoranthene influences endogenous abscisic acid level and primary photosynthetic processes in pea (Pisum sativum L.) plants in vitro. Plant Growth Regulation, 57(1): 39-47.

Wahid A, Arshad M, Farooq M, 2010. Cadmium phytotoxicity: Responses, mechanisms and mitigation strategies: A review. In: Organic Farming, Pest Control and Remediation of Soil Pollutants (Lichtfouse E, ed.). Springer, the Netherlands. 371-403.

Wetzel A, Alexander T, Brandt S, Haas R, Werner D, 1994. Reduction by fluoranthene of copper and lead accumulation in Triticum aestivum L. Bulletin of Environmental Contamination and Toxicology, 53(6): 856-862.

Willan R L, FAO (Agriculture Organization of the United Nations), 1985. A Guide to Forest Seed Handling: with Special Reference to the Tropics. Food and Agriculture Organization of the United Nations, Italy.

Zhang H, Dang Z, Zheng L C, Yi X Y, 2009. Remediation of soil co-contaminated with pyrene and cadmium by growing maize (Zea mays L.). International Journal of Environmental Science and Technology, 6(2): 249-258.

Zhang Z H, Rengel Z, Meney K, Pantelic L, Tomanovic R, 2011. Polynuclear aromatic hydrocarbons (PAHs) mediate cadmium toxicity to an emergent wetland species. Journal of Hazardous Materials, 189(1-2): 119-126. 